techniques to the rebuilding of alveolar ridges by bone and skin grafts deserves special mention.

In these days of terrorist attacks, any surgeon may be faced with missile injuries. The lessons in this book, therefore, are well worth general study. There are, perhaps, ways in which it could be improved. Multiple authorship leads to variation in style unless editorial revision is thorough. To the English reader one chapter in particular is heavy-going. A substantial amount of data has been accumulated and there are sizeable tables of figures. Unfortunately figures are often quoted to 2 places of decimals which should have been rounded up to the nearest whole number. These tables break up the text and reduce its impact. A few important statistics should have been quoted and the rest assembled in the appendix. The Ciba coloured plates illustrating the anatomy of the head and neck are also not strictly relevant despite their quality and again break up the flow of the text.

At the end there is a sizeable appendix and it is devoted to discussions of possible research projects related to severe cranio-facial disfigurement. Quite frankly, many of these seemed to have doubtful value and application.

There is no doubting the overall value of this book, and by modern standards it is most reasonably priced. If at some time a second edition is contemplated perhaps a shortened version could be produced, written in traditional text book form.

\section{MCQ Tutor: MRCOG Part 1 Basic Sciences as Applied to Obstetrics and Gynaecology}

By V. R. Tindall. Pp. 180, soft cover. William Heinemann Medical Books, London, 1978. $£ 3.75$.

This book is exactly what it claims to be, namely a collection of carefully selected and neatly set-out multiple choice questions such as may be posed in the part I examination for membership of the Royal College of Obstetricians and Gynaecologists. Answers are provided overleaf, and separate answer sheets at the end of the book, with an explanation of the marking system, allow self-examination and assessment.

There can be no substitute for sound factual knowledge before the sitting of this examination, but this book will serve as a useful guide as to what knowledge is required. It should also allow the prepared candidate to check that his knowledge is adequate and without gaps. It would be especially valuable to those candidates who have not been trained in the basic sciences in this country.

In summary this book is a useful aid for all part I MRCOG candidates.

\section{The New Health Practitioners in America. A Comparative Study}

By B. L. Reedy. Pp. 79, soft cover. King's Funds Books, Pitman Medical Publishing Co Ltd, London, 1978. $£ 4.50$.

This book, produced on A4 paper, includes 38 pages of text with subsequent pages devoted to various appendices, references and indexing.

Dr Reedy applies himself to a discussion of the New Health Practitioner (NHP) in the United States and includes comparisons, wherever relevant, to the situation in Britain. He starts with a description of the term NHP which can be taken to include 2 distinct kinds of worker, the physician's assistant (PA) and the nurse practitioner (NP) A brief description of the development of medical services in the U.S.A. sets the scene for the evolution of the NHP. This, to a marked extent, was in response to the increasing trend in the $1950 \mathrm{~s}$ and 1960 s for American doctors to enter the specialities, coupled with their subsequent maldistribution. (In 1940 G.P.s formed $76 \%$ of all physicians compared to $36 \%$ in 1965 ).

The descriptions of the physician's assistant and the nurse practitioner include practical examples of their training and fields of activity. The differences between the 2 generic groups of workers are clearly drawn, as are the areas of inter- $\vec{\Phi}$ professional friction. These frictions in combination with the $\varrho$ licensure and regulations have served further to delineate the $C$ differences between the 2 groups. The PAs by willingly accepting a dependent role to physicians have, in fact, $\stackrel{\vec{\oplus}}{\rightarrow}$ achieved greater freedom and flexibility. Indeed, some of the job specifications for PAs appear very similar to those of $\frac{\bar{\sigma}}{\sigma}$ British house officers.

However, the future of the PA, faced with incomplete $\frac{\overline{\mathcal{S}}}{\vec{\rho}}$ acceptance by some doctors and the unhelpful and sometimes $\mathbb{Q}$ obstructive attitude of the American Nurses' Association, is by no means assured. With the recent growth in American $\infty$ physician training schemes in general practice, and govern- $\vec{\circ}$ ment moves to correct maldistribution of services, it is difficult to be very optimistic.

On the other hand, Nurse Practitioners appear to be far $\vec{\sigma}$ more secure and the author suggests in his conclusion that $\frac{\partial}{\varnothing}$ the experience in America might be used to good effect in the involvement of nurses in the British health care teams of the 3 . future.

This reviewer found this conclusion disappointing. One of $\mathrm{Gr}$ the criticisms of some of the NHP courses in America is that $\stackrel{\perp}{\perp}$ of timidity of approach - could this not also be true of $\infty$ Britain? One is left with the uncomfortable feeling that in the U.K. the whole concept of the NHP, and particularly the PA, N has proceeded by default. The implications of this to the $O$ future direction of health care systems are obvious and of great importance. The role of the NHP has been approached with imagination in other countries. This book should be $\overrightarrow{0}$ widely read and the whole concept thoroughly considered with particular reference to the National Health Service.

\section{Ovarian Carcinoma. Etiology, Diagnosis and Treatment}

By H. R. K. BARber. Pp. 326, illustrated. Masson Pu lishing, Tunbridge Wells: Abacus Press, 1978. $£ 26.35$. This must be a most difficult subject of which to provide comprehensive text book and Dr Barber must have come closer than most should this have been his aim. This reviewer fears that because the author has offered so much more than a current review on this rapidly advancing subject, the text is not easily going to be kept up to date. While he has tried $\frac{\mathbb{Q}}{8}$ hard to put forward prevailing opinions, his own are naturally foremost, and very valuable these must be when based on $\underline{\overrightarrow{0}}$ such a wealth of experience. It is most noticeable in the 3 chapter on pre- operative evaluation and work-up, that these $\vec{T}$ opinions are from across the Atlantic. It was a disappointment not to find more figures to support the value of the sometimes extensive investigations and treatments the $\frac{\partial}{3}$ patients were offered, and what figures there were tended to be concealed in the text. Some of the few illustrations did not $\frac{5}{3}$ contribute greatly to the text.

It is hoped that these few observations will not be considered impertinent when Dr Barber has already been $\frac{0}{3}$ extensively congratulated on this considerable work by distinguished men in his field. The book would add greatly to the gynaecological reference section at any medical library and should be of benefit to all practising clinicians and their
patients.

\section{Pineal Tumors}

Edited by Henry H. Schmidek. Pp. 138, illustrated. N New York, etc: Masson Publishing, Tunbridge Wells: $\omega$ Abacus Press, 1978. £22.80.

This is a first volume in a series intended to bring recent $\mathscr{O}$ advances in diagnosis and treatment of cancer to specialists practising in particular areas, in this case neurologists and $\stackrel{\mathscr{C}}{+}$ neurosurgeons. Eight contributors, all from the United States, have written 7 Chapters covering the pathology,

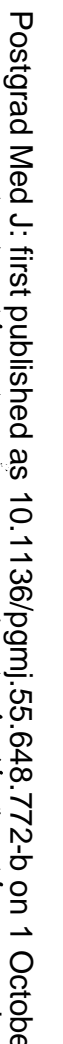
(1) 